\title{
EFFECTS OF ERICOID MYCORRHIZAL FUNGI OR DARK SEPTATE ENDOPHYTIC FUNGI ON THE SECONDARY METABOLITE OF RHODODENDRON PSEUDOCHRYSANTHUM (R. MORII) SEEDLINGS
}

\author{
LIN, L.-C. ${ }^{*}-$ LIN, C.-Y. ${ }^{2}-$ LIN, W.-R. ${ }^{3}-$ TUNG, Y.-T. ${ }^{4 *}-$ WU, J.-H. ${ }^{2 *}$ \\ ${ }^{1}$ Department of Forestry and Natural Resources, National Chiayi University, Chiayi 600, \\ Taiwan \\ (phone: +886-5-271-7474; fax: +886-5-271-7467) \\ ${ }^{2}$ Department of Forestry, National Chung Hsing University, Taichung 402, Taiwan \\ ${ }^{3}$ Bioresource Collection and Research Center (BCRC), Food Industry Research and \\ Development Institute (FIRDI), Hsinchu 300, Taiwan
}

${ }^{4}$ Graduate Institute of Metabolism and Obesity Sciences, Taipei Medical University, Taipei 110, Taiwan

*Corresponding authors

e-mail:linerm@mail.ncyu.edu.tw; f91625059@tmu.edu.tw; eric@nchu.edu.tw

(Received 12 $2^{\text {th }}$ Oct 2020; accepted $21^{\text {st }}$ Dec 2020)

\begin{abstract}
We investigated the effects of ericoid mycorrhizal fungi (ERMFs) or dark septate endophytic fungi (DSEFs) on secondary metabolite production and growth promotion of Rhododendron pseudochrysanthum. The strains Rf9 (Cryptosporiopsis sp.) and Rf32 (Cryptosporiopsis sp.) were isolated from Rhododendron formosanum, whereas strains Rp7 (Phialocephala fortinii), Rp9 (Hyaloscyphaceae sp.), and Rp28 (Phialocephala fortinii) were isolated from $R$. pseudochrysanthum (R. morii). We studied their molecular relationships using phylogenetic analysis and divided these five strains into three groups (Cryptosporiopsis sp., Phialocephala fortinii, and Hyaloscyphaceae sp.). We found that strains Rf9 and Rf32 belonged to ERMFs, which form a hyphal complex with R. pseudochrysanthum, whereas strains Rp7, Rp9, and Rp28 belonged to DSEFs, which form microsclerotia on $R$. pseudochrysanthum. The endophytic fungi can promote the growth of $R$. pseudochrysanthum seedlings, and the total fresh weight of inoculated seedlings was higher than that of the control seedlings. In addition, the phytochemical profile showed that the methanolic extract of Rp7-inoculated seedlings had the highest content of rutin, hyperoside, quercitrin, and $(2 R, 3 S)$-catechin among all inoculated seedlings. In conclusion, DSEFs and ERMFs promoted the growth response and secondary metabolite production of $R$. pseudochrysanthum seedlings.
\end{abstract}

Keywords: ericoid mycorrhiza, dark septate endophyte, growth response, phytochemical, Rhododendron pseudochrysanthum

\section{Introduction}

Rhododendron is a large genus of the family Ericaceae (Yang et al., 1999; Wu et al., 2003) with approximately 1,200 native Rhododendron species reported worldwide (Chamberlain et al., 1996). Both low and high elevations in Taiwan show a wide distribution of Rhododendron, and 15 indigenous species have been identified (Tseng and $\mathrm{Lu}, 2003$ ), with most of their leaf extracts exhibiting excellent antioxidant activities (Lin et al., 2014a). Mycorrhizae are root associations synthesized between plants and fungi; $98 \%$ of all plant species have symbiotic fungal partners associated with their root systems (Bonfante and Genre, 2010). Mycorrhizal associations present in various forms are ubiquitous in nature and play crucial roles in plant nutrition and nutrient cycling. They 
also influence the structure and dynamics of the plant communities within which they exist (Cairney and Meharg, 2003). The species of the family Ericaceae can form ericoid mycorrhizae (ERM) with ericoid mycorrhizal fungi (ERMFs) (Davies et al., 2003), which help their host plants gain more nutrients under stressful conditions (Schmid et al., 1995; Rice and Currah, 2001; Piercey et al., 2002; Lin et al., 2011). Therefore, ERM improves the host plants' competitiveness at the ecosystem level (Michelsen et al., 1996). In addition, ericaceous plants are frequently associated with dark septate endophytic fungi (DSEFs), which are also beneficial to host plants to obtain nutrients (Jumpponen and Trappe, 1998).

Recent studies have demonstrated the ability of mycorrhizal fungi and DSEFs to enhance secondary metabolite contents of their host plants. For instance, arbuscular mycorrhizal fungi could increase the berberine content in Phellodendron chinense (Zhou and Fan, 2007); moreover, DSEF (EF-37) could promote the growth and increase flavonoid content in its host plant, Saussurea involucrate (Wu et al., 2010). Rhododendron species contain numerous antioxidative phenolic compounds that could be developed into pharmaceutical products (Qiang et al., 2011). Of 10 common indigenous Rhododendron species in Taiwan, Rhododendron pseudochrysanthum (R. morii) has demonstrated the most efficient antioxidant activities (Lin et al., 2014a). Although ERMFs and DSEFs promote growth, survival, and competition in Rhododendron species, no research has focused on the growth response and phytochemical profile of Rhododendron seedlings with ERMFs or DSEFs to the best of our knowledge. Therefore, we assessed the effect of five varieties of endophytic fungi (mycorrhiza or dark septate) on plant biomass and its ability to produce secondary metabolites of $R$. pseudochrysanthum in this study.

\section{Material and Methods}

\section{Seeds}

R. pseudochrysanthum seeds were collected from the Alishan Forest Recreation Area in Chiayi City, Taiwan (longitude, $120^{\circ} 48^{\prime} 3^{\prime \prime} \mathrm{E}$; latitude, $23^{\circ} 31^{\prime} 10^{\prime \prime} \mathrm{N}$; altitude, $2,189 \mathrm{~m}$ ). The seeds were obtained from the capsule of $R$. pseudochrysanthum. The average fresh weight of per hundred seeds was $27.3 \pm 1.8 \mathrm{mg}$.

\section{Endophytic fungi}

We used five strains of endophytic fungi in this study: Strains Rf9 and Rf32 are ericoid mycorrhizal fungi, capable of forming ericoid mycorrhiza with Formosan rhododendron (Lin et al., 2011), and strains Rp7, Rp9, and Rp28 from R. pseudochrysanthum (Lin et al., 2014b). For inoculation, these five strains were transferred to $2 \%$ malt extract agar ( $2 \%$ MEA: malt extract, $20 \mathrm{~g} / \mathrm{L}$; agar, $15 \mathrm{~g} / \mathrm{L}$ ) plates and incubated in growth chambers at $23^{\circ} \mathrm{C}$ after 21 days.

\section{DNA extraction, sequencing and phylogenetic analysis}

Total DNA was extracted from the mycelium using the cetyl trimethyl ammonium bromide (CTAB) method (Doyle and Doyle, 1990). The rDNA ITS region was amplified with the primers V9G and LR1 (Vilgalys and Hester, 1990; De Hoog and van den Ende, 1998). An ABI PRISM 3730 Genetic Analyzer (PE Applied Biosystems, Foster City, CA, USA) was used to directly sequence PCR products. Sequence data for the ITS regions 
was compared with sequences deposited in NCBI GenBank by BLAST, using the default settings. We assigned names to the sequences according to the following criteria: (1) sequence identity of $\geq 98.0 \%$; (2) $\geq 1.0 \%$ separations from the next closest species; ( 3 ) $\geq 95.0 \%$ sequence coverage for the matching sequence; and (4) matching sequence published in a peer-reviewed journal article or submitted by the culture collection centers (CLSI, 2008).

\section{Pure resynthesis and growth responses}

Pure resynthesis was performed using the method of Dalpé (Dalpé, 1986; Lin et al., 2011; Okane et al., 2012). with some modifications. After surface cleaning, $R$. formosanum seeds were sterilized in $30 \%$ hydrogen peroxide solution for $90 \mathrm{~s}$, rinsed three times in sterilized distilled water, and then incubated in 9-cm petri dishes containing $1 \%$ water agar for germination. Germinated seedlings were transplanted to modified Mitchell and Read medium $\left(\mathrm{NH}_{4} \mathrm{Cl}, 32 \mathrm{mg} / \mathrm{L} ; \mathrm{CaCl}_{2} \cdot 7 \mathrm{H}_{2} \mathrm{O}, 43.5 \mathrm{mg} / \mathrm{L} ; \mathrm{MgSO}_{4} \cdot 7 \mathrm{H}_{2} \mathrm{O}\right.$, $10 \mathrm{mg} / \mathrm{L} ; \mathrm{KCl}, 5.5 \mathrm{mg} / \mathrm{L} ; \mathrm{FeCl}_{3}, 3.75 \mathrm{mg} / \mathrm{L}$; sucrose, $2 \mathrm{~g} / \mathrm{L} ; \mathrm{KH}_{2} \mathrm{PO}_{4}, 210 \mathrm{mg} / \mathrm{L}$; pyridoxine, $100 \mu \mathrm{g} / \mathrm{L}$; thiamine, $100 \mu \mathrm{g} / \mathrm{L}$; agar, $10 \mathrm{~g} / \mathrm{L}$ ). When the germinated seedlings had two cotyledons, all aseptic seedlings were inoculated with Rf9, Rf32, Rp7, Rp9, and Rp28 strains, whereas no inoculated seedlings were used as the control. A growth chamber was used to grow all the seedlings $\left(22{ }^{\circ} \mathrm{C}, 65 \%\right.$ relative humidity, and $16 \mathrm{~h}$ of light with a maximum illumination of 5000 lux). The seedlings were carefully removed from their substrate after incubation for 12 months to measure the effects of all treatments on the growth performance of seedlings. Each treatment had four replicates, and the fresh weight was measured.

\section{Morphology of root association}

The roots of all treatments were sampled and cleaned with water (Upson et al., 2007). A stereomicroscope was used to observe root morphology (Usuki and Narisawa, 2005). The roots were cleaned in $10 \% \mathrm{KOH}$ for $24 \mathrm{~h}$, washed in $\mathrm{dH}_{2} \mathrm{O}$, acidified in $10 \% \mathrm{HCl}$ for $1 \mathrm{~h}$, and stained by transferring to $0.05 \%$ aniline blue (aniline blue, $0.25 \mathrm{~g} ; \mathrm{dH}_{2} \mathrm{O}, 25 \mathrm{~mL}$; lactic acid, $475 \mathrm{~mL})$ for $1 \mathrm{~h}$ and then to the destaining solution $\left(\mathrm{dH}_{2} \mathrm{O}, 25 \mathrm{~mL}\right.$; lactic acid, $475 \mathrm{~mL}$ ) for $2 \mathrm{~h}$. They were then mounted on microscope slides in lactoglycerol (lactic acid:glycerol: $\mathrm{dH}_{2} \mathrm{O}=14: 1: 1, \mathrm{v} / \mathrm{v} / \mathrm{v}$ ) (Hutton et al., 1994).

\section{Extraction, isolation, and quantification}

The extraction and isolation of secondary metabolites from $R$. pseudochrysanthum shoots were performed using our previously reported method (Lin et al., 2014a). Each fresh sample was chopped into small pieces, and secondary metabolites were extracted using methanol by soaking the samples two times for one week at room temperature $\left(25^{\circ} \mathrm{C}\right)$. The resulting methanolic extracts were decanted and filtered using Whatman No. 1 filter paper. After concentrating the filtrates in a rotary evaporator, they were lyophilized. The phytochemicals of each sample were quantified through high-performance liquid chromatography (HPLC) on a Jasco PU-2080 instrument (Tokyo, Japan) with a $250 \mathrm{~mm}$ length $\times 4.6 \mathrm{~mm}$ i.d. and a $5-\mu \mathrm{m}$ Supelco RP-amide column (Bellefonte, PA, USA). The mobile phase consisted of solvents A and B comprising $100 \% \mathrm{MeOH}$ and ultrapure water, respectively. The elution conditions were $0-10 \mathrm{~min}$ of $30-36 \%$ A followed by $10-50 \mathrm{~min}$ of $36-72 \% \mathrm{~A}$, all at a flow rate of $0.75 \mathrm{~mL} / \mathrm{min}$, on a Jasco MD-2010 photodiode array detector (Tokyo, Japan) at a $280 \mathrm{~nm}$ 
wavelength. In total, we isolated and identified six specific phytochemicals, namely, $(2 R, 3 S)$-catechin, $\quad(2 R, 3 R)$-dihydromyricetin $\quad 3-O-\beta$-L-arabinopyranoside, $(2 R, 3 R)$-taxifolin 3- $O$ - $\beta$-L-arabinopyranoside, rutin, hyperoside, and quercitrin (Lin et al., 2014a). In addition, standard stock solutions of compounds were prepared in methanol, filtered through Millipore filters $(0.45 \mu \mathrm{m})$, and appropriately diluted to obtain the desired concentrations in the quantification range for preparing the calibration curve for quantifying these phytochemicals in $R$. pseudochrysanthum shoots. The calibration graphs were plotted after the linear regression of the peak areas versus concentrations.

\section{Statistical analysis}

All statistical analyses were performed using the software Statistical Package for the Social Science (SPSS 12.0) (Chicago, IL, USA) for Windows. The significance of difference was calculated using the Tukey's test, and statistical significance was set at $p<0.05$.

\section{Results and Discussion}

\section{Phylogenetic analysis}

According to previous ecological studies of endophytic fungi, 90\%-95\% ITS sequence similarity is often used as a species boundary in fungi (Arnold et al., 2009; Okane et al., 2012). The query coverage and maximum identity of endophytes isolated from Rhododendron with their most closely related fungal ITS sequences in GenBank are presented in Table 1. In European rhododendrons roots had been demonstrated frequent interactions between ERMFs and dark septate endophytes (DSE) and a morphological continuum between ERM and DSE associations (Vohník and Albrechtová, 2011). Among the five endophytic fungi used in this study (Fig. 1), the strains Rp7 and Rp28 were isolated from $R$. pseudochrysanthum and closed to Phialocephala fortinii. P. fortinii, a DSEF (Lukešová et al., 2015), has been frequently isolated from ericaceous plants (Hambleton and Currah, 1997). In addition, the strain Rp9 was closed to Hyaloscyphaceae sp. with 97\% ITS sequence similarity (Table 1). Rf9 and Rf32 were closely related to Cryptosporiopsis and Pezicula; however, Cryptosporiopsis species are anamorphs of ascomycetes in the genera Pezicula and Neofabraea (Dermataceae) (Sigler et al., 2005). Thus, both Rf9 and Rf32 were still closely related to Cryptosporiopsis.

Table 1. Endophytes isolated from Rhododendron species in Taiwan

\begin{tabular}{c|c|c|c|c}
\hline \multirow{2}{*}{ Isolates } & \multicolumn{4}{|c}{ GenBank sequences } \\
\cline { 2 - 5 } & Blast results & $\begin{array}{c}\text { Accession } \\
\text { No. }\end{array}$ & $\begin{array}{c}\text { Query } \\
\text { coverage }\end{array}$ & Maximum identity \\
\hline Rf9 & Cryptosporiopsis sp. & JF519423 & $99 \%$ & $94 \%$ \\
Rf32 & Cryptosporiopsis sp. & JF519423 & $99 \%$ & $94 \%$ \\
Rp7 & Phialocephala fortinii & EU882733 & $99 \%$ & $98 \%$ \\
Rp9 & Hyaloscyphaceae sp. & AB986449 & $98 \%$ & $97 \%$ \\
Rp28 & Phialocephala fortinii & EU882733 & $99 \%$ & $98 \%$ \\
\hline
\end{tabular}

GenBank accession number of the rDNA ITS sequence of the isolates used in this study and the query coverage and maximum identity with their most closely related fungal ITS sequences in GenBank are given 


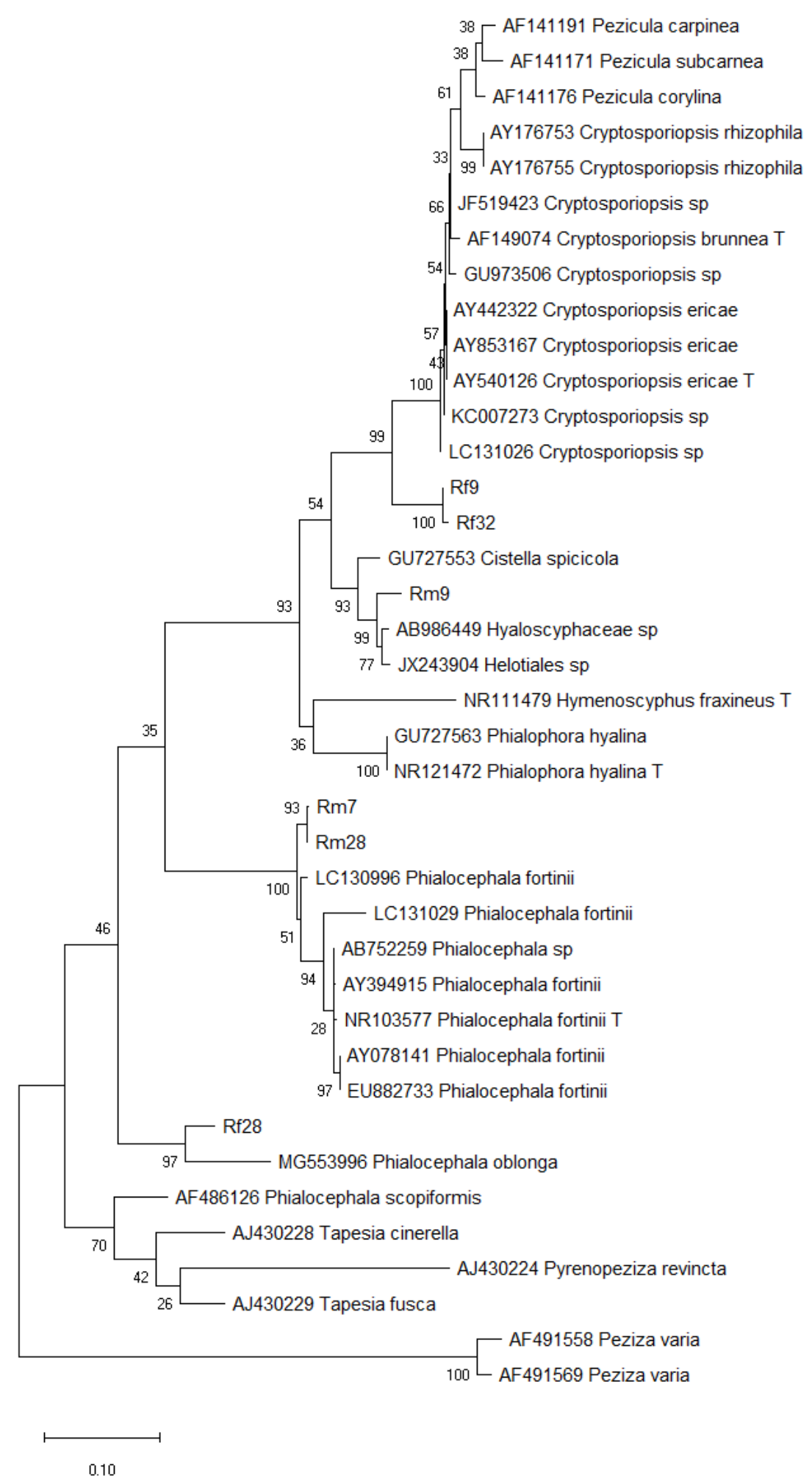

Figure 1. Maximum likelihood phylogenetic tree based on internal transcribed spacer rDNA sequence data from these two endophytes, including fungal species from GenBank with high sequence similarities. $T=$ sequence from Ex-type or type isolate. Isolates $R p 7$ and $R p 28$ clustered with Phialocephala fortinii with high bootstrap values $(M L=100 \%)$. Rp 9 was identified as Hyaloscyphaceae sp.; isolates $R f 9$ and $R f 32$ were closely related to Cryptosporiopsis 


\section{Morphology and colonization of $R$. pseudochrysanthum in resynthesized seedlings}

Rhododendron seedlings are a slow-growing species and must have ERMFs to promote their growth (Lin et al., 2011, 2019, 2020; Okane et al., 2012; Wei et al., 2016, 2020). All resynthesized seedlings survived after 12 months of incubation (Fig. 2). The root-related features of all treatments were observed under light microscopy (Fig. 3). Seedlings inoculated with Rf9 and Rf32 grew well (Fig. 2A,B). Brown root associations were identified using stereomicroscopy $(F i g .3 A, C)$, with specific ERMF characteristics of the hyphal complex observed in the stained roots (Fig. 3B,D). Similarly, Fig. 2C-E illustrates that Rp7-, Rp9-, and Rp28-inoculated seedlings also grew well; however, dark brown (Fig. 3E), light brown (Fig. 3G), and black root associations (Fig. 3I) were observed by stereomicroscopy. Moreover, specific DSEF characteristics of melanized (Fig. 3F), hyaline (Fig. 3H), and melanized and hyaline microsclerotia-like structures (Fig. 3J) were found in the stained roots of Rp7-, Rp9-, and Rp28-inoculated seedlings, respectively. The control seedlings were smaller than all those of the inoculated groups as expected (Fig. 2F), and light microscopy showed hyaline roots before (Fig. 3K) and after staining (Fig. 3L).
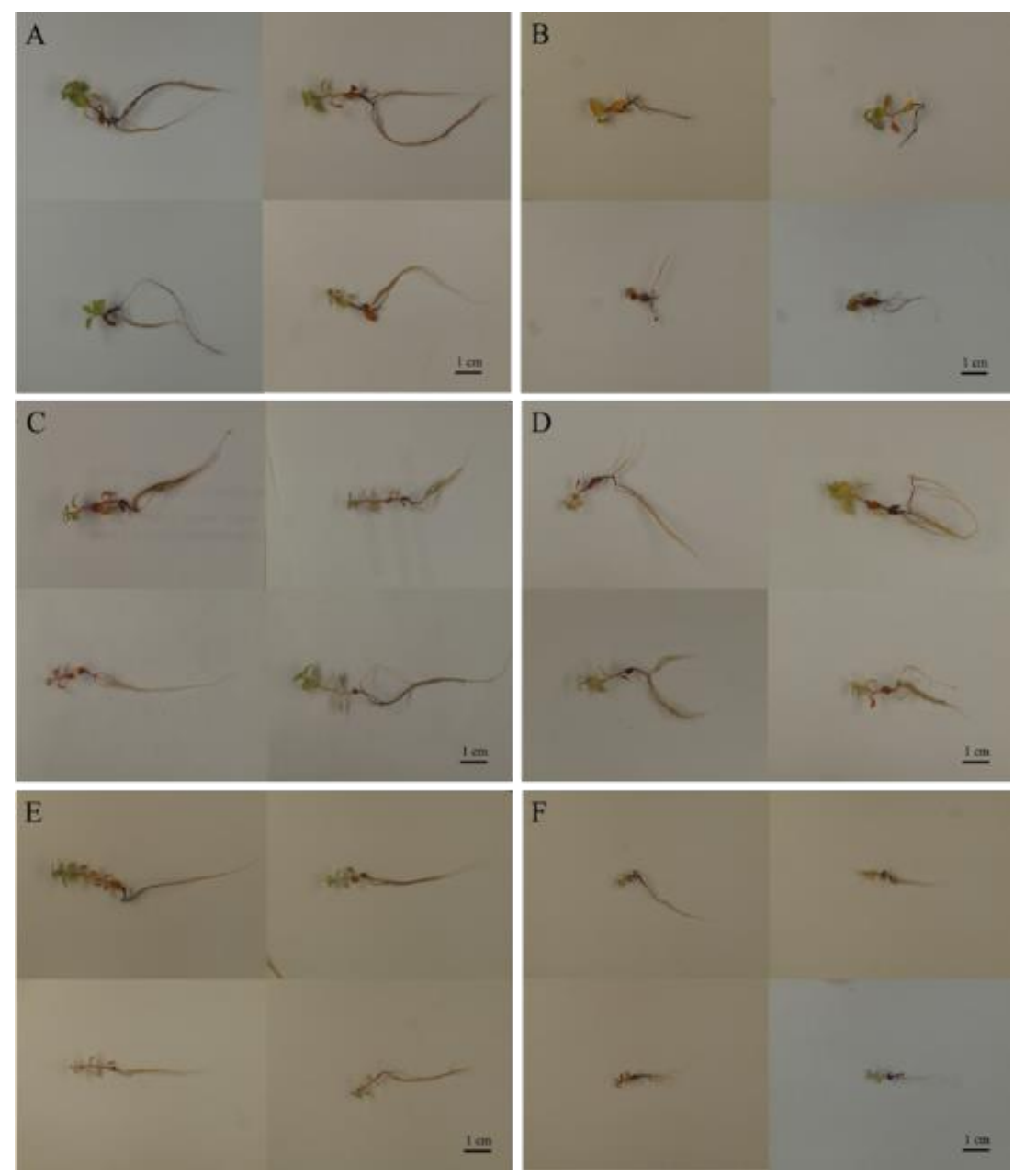

Figure 2. Morphology of mycorrhizal synthesis of Rhododendron pseudochrysanthum seedlings after 12 months of incubation. A, Rf9-inoculation. B, Rf32-inoculation. C, Rp7-inoculation. D, Rp9 inoculation. E, Rp28-inoculation. F, control 


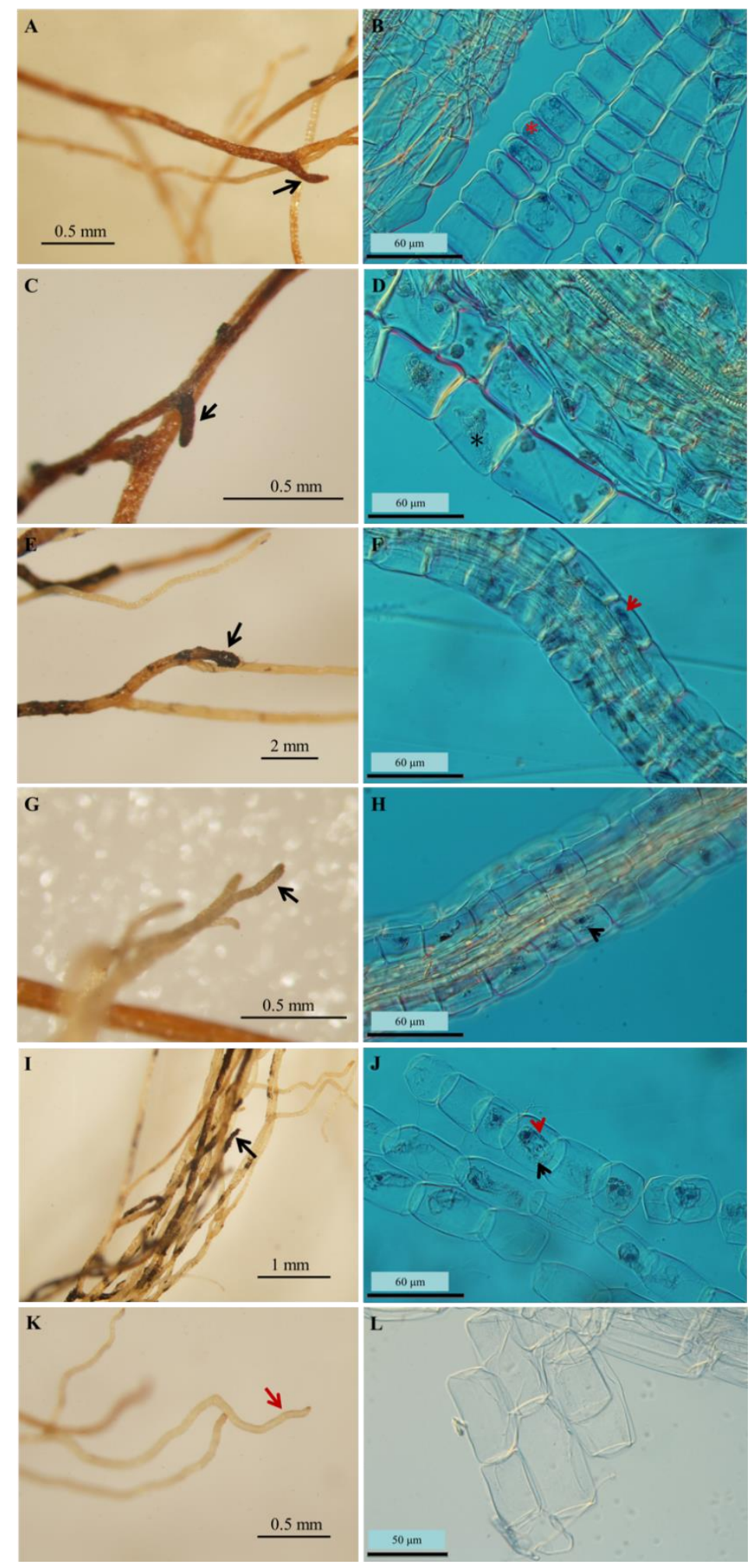

Figure 3. Root association and stain of Rhododendron pseudochrysanthum seedlings after 12 months incubation. A and B, Rf9 inoculation. $C$ and D, Rf32 inoculation. E and F, Rp7 inoculation. $G$ and H, Rp9 inoculation. I and J, Rp28 inoculation. K and L, control. Red *: hyphae complex, black *: hyphae complex-like, red arrowhead: melanized microsclerotia-like, black arrowhead: hyaline microsclerotia-like, black arrow: root association, and red arrow: root 


\section{Growth responses of $R$. pseudochrysanthum}

The results of growth responses indicated that all treated seedlings showed a positive effect after incubation for 12 months as demonstrated in Fig. 2. The Rp9 inoculation had the highest average shoot fresh weight; this value then decreased in the following order: Rp28 inoculation $>\mathrm{Rp} 7$ inoculation $>\mathrm{Rf} 9$ inoculation $>\mathrm{Rf} 32$ inoculation $>$ and control (Table 2). By contrast, after the 12-month incubation, the seedlings' average root fresh weight decreased in the following order: Rp28 inoculation $>$ Rp7 inoculation $>$ Rp9 inoculation > Rf9 inoculation > Rf32 inoculation > control. Moreover, the average total fresh weight of all inoculations was significantly greater than that of the control as given in Table 2.

Table 2. Fresh weight of Rhododendron pseudochrysanthum seedlings with different treatments after 12-month incubation

\begin{tabular}{c|c|c|c|c}
\hline \multirow{2}{*}{ Treatment } & \multicolumn{3}{|c|}{ Fresh weight (mg) } & \multirow{2}{*}{ S/R } \\
\cline { 2 - 4 } & Shoot & Root & Total & \multirow{2}{*}{$4.2 \pm 1.1^{\mathrm{ab}}$} \\
\hline Control & $6.5 \pm 0.5^{\mathrm{a}}$ & $2.0 \pm 0.6^{\mathrm{a}}$ & $8.5 \pm 1.0^{\mathrm{a}}$ & $2.9 \pm 0.8^{\mathrm{ab}}$ \\
Rf9 & $16.5 \pm 1.2^{\mathrm{ab}}$ & $7.5 \pm 2.4^{\mathrm{abc}}$ & $24.0 \pm 3.4^{\mathrm{b}}$ & $5.8 \pm 1.1^{\mathrm{b}}$ \\
Rf32 & $16.3 \pm 2.5^{\mathrm{ab}}$ & $3.3 \pm 0.8^{\mathrm{ab}}$ & $19.5 \pm 3.2^{\mathrm{ab}}$ & $2.1 \pm 0.8^{\mathrm{a}}$ \\
Rp7 & $16.8 \pm 3.8^{\mathrm{ab}}$ & $9.5 \pm 1.4^{\mathrm{c}}$ & $26.3 \pm 3.0^{\mathrm{b}}$ & $2.1 \pm 0.4^{\mathrm{a}}$ \\
Rp9 & $17.3 \pm 2.1^{\mathrm{b}}$ & $9.3 \pm 1.3^{\mathrm{bc}}$ & $26.5 \pm 0.9^{\mathrm{b}}$ & $1.8 \pm 0.4^{\mathrm{a}}$ \\
Rp28 & $17.0 \pm 2.3^{\mathrm{b}}$ & $10.0 \pm 0.8^{\mathrm{c}}$ & $27.0 \pm 1.8^{\mathrm{b}}$ & \\
\hline
\end{tabular}

All values are means \pm standard error $(n=4)$. Different superscript letters $(a, b, c)$ within a column indicate significant difference at $p<0.05$

\section{The composition and content of secondary metabolites}

As previously reported Rhododendron species are rich in antioxidative phytochemicals, especially flavonoids (Jung et al., 2007; Nirmala and Ramanathan, 2011; Qiang et al., 2011). R. pseudochrysanthum exhibits the best antioxidant activity of the 10 indigenous Rhododendron species in Taiwan. We isolated and identified the following six specific phytochemicals from wild-type $R$. pseudochrysanthum leaves in our previous study: $(2 R, 3 S)$-catechin (1), $(2 R, 3 R)$-dihydromyricetin 3- $O$ - $\beta$-L-arabinopyranoside (2), $(2 R, 3 R)$-taxifolin 3- $O-\beta$-L-arabinopyranoside (3), rutin (4), hyperoside (5), and quercitrin (6) (Lin et al., 2014a). However, the chemical compositions of these phytochemicals were different between all inoculated seedlings and the control as well as from each other after the 12-month incubation as shown in Fig. 4. Few weak signals were observed in the HPLC profile of the control group. The control seedlings only get basic nutrients and are less irritating to plants, so there are almost no secondary metabolites. All mycorrhizal seedlings of $R$. pseudochrysanthum exhibited stronger signals in HPLC profiles compared with the control seedlings, especially for the peaks of rutin, hyperoside, and quercitrin. Moreover, the Rf32 strain is good at promoting plant growth. But this is not conducive to promoting the secondary metabolites of plants. Therefore, the secondary metabolites of $R$. pseudochrysanthum seedlings are affected by mycorrhiza.

In addition, the phytochemical level of seedlings inoculated with DSEFs was higher than that of seedlings inoculated with ERMFs. The phytochemicals $(2 R, 3 S)$-catechin and $(2 R, 3 R)$-taxifolin 3-O- $\beta$-L-arabinopyranoside were only detected in Rp7-inoculated seedlings. Moreover, six quantitative analytes in various methanolic extracts of 
R. pseudochrysanthum seedlings were determined through HPLC. Among all treatments, the extract of Rp7-inoculated seedlings exhibited the highest phytochemical content as shown in Table 3. The contents of $(2 R, 3 S)$-catechin, rutin, hyperoside, and quercitrin were $27.2 \pm 2.4,136.5 \pm 20.6,23.6 \pm 2.3$, and $55.4 \pm 6.5 \mu \mathrm{g}$ per milligram of methanolic extract, respectively. By contrast, these phytochemicals were almost not detected in the control sample.

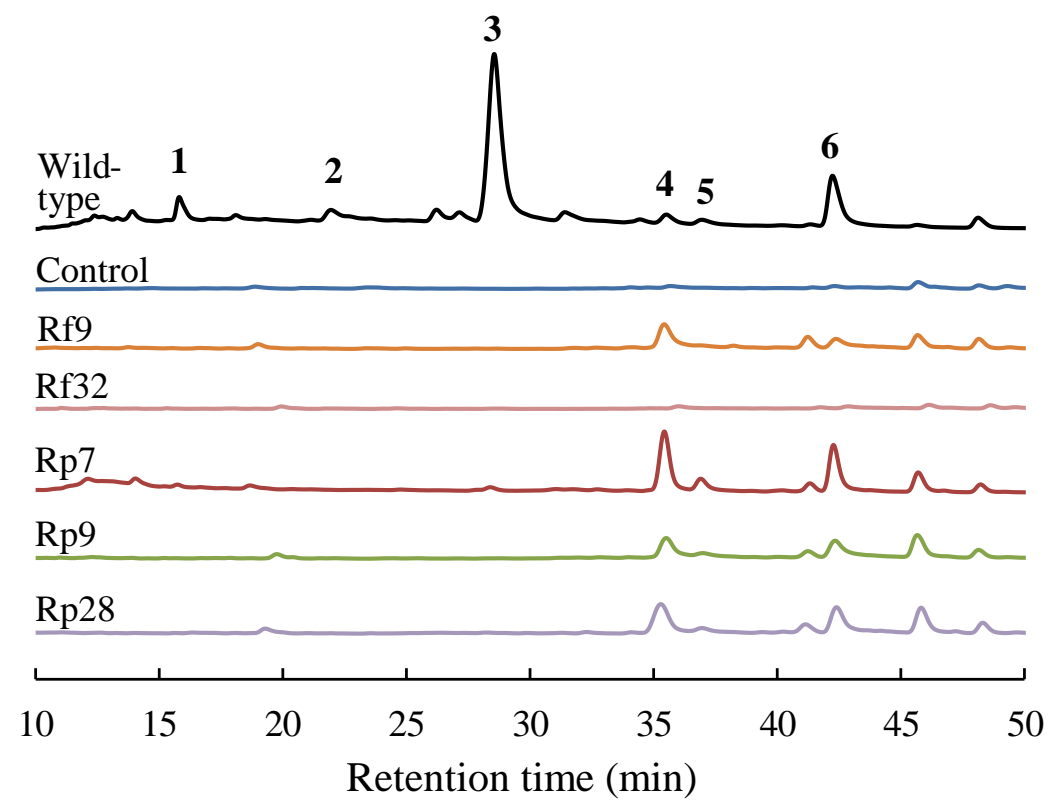

Figure 4. HPLC profiles of methanolic extracts from Rhododendron pseudochrysanthum seedlings inoculated with different ericoid mycorrhizal fungi. 1: $(2 R, 3 S)$-catechin, 2: $(2 R, 3 R)$ dihydromyricetin 3-O- $\beta$-L-arabinopyranoside, 3: $(2 R, 3 R)$-taxifolin 3-O- $\beta$-L-arabinopyranoside, 4: rutin, 5: hyperoside, and 6: quercitrin

Table 3. Contents of major phytochemicals from the methanolic extracts of Rhododendron pseudochrysanthum seedlings inoculated with various ericoid mycorrhizal fungi and dark septate endophytic fungi

\begin{tabular}{c|c|c|c|c|c|c}
\hline \multirow{2}{*}{ Treatment } & \multicolumn{7}{|c}{ Phytochemical content $(\boldsymbol{\mu g} / \mathbf{m g}$ of methanolic extract) } \\
\cline { 2 - 7 } & $\mathbf{1}$ & $\mathbf{2}$ & $\mathbf{3}$ & $\mathbf{4}$ & $\mathbf{5}$ & $\mathbf{6}$ \\
\hline Control & ND & ND & ND & Trace & Trace & ND \\
Rf9 & ND & ND & ND & $53.3 \pm 11.5$ & Trace & $19.0 \pm 3.2$ \\
Rf32 & ND & ND & ND & Trace & Trace & Trace \\
Rp7 & $27.2 \pm 2.4$ & ND & Trace & $136.5 \pm 20.6$ & $23.6 \pm 2.3$ & $55.4 \pm 6.5$ \\
Rp9 & ND & ND & ND & $51.2 \pm 11.7$ & $14.2 \pm 1.4$ & $31.1 \pm 5.8$ \\
Rp28 & ND & ND & ND & $44.8 \pm 10.9$ & $11.8 \pm 1.9$ & $26.1 \pm 3.6$ \\
\hline
\end{tabular}

Results area mean \pm standard deviation $(n=3) .{ }^{*} \mathrm{ND}$ : Not detected

The ubiquitous mycorrhizal associations are essential for plant nutrition and nutrient cycling (Schmid et al., 1995; Cairney and Meharg, 2003; Gibson and Mitchell, 2005; Johansson, 2011; Lin et al., 2011). The five strains (Rf9, Rf32, Rp7, Rp9, and Rp28) used in this study were demonstrated to belong to Helotiales. Rf9 and Rf32 and Rp7, Pp9, and Rp28 were ERMFs and DSEFs, respectively. All of them demonstrated a significant 
increase in fresh weight by $129 \%-212 \%$ compared with the control group. This result revealed that the growth of $R$. pseudochrysanthum seedlings could be improved by inoculation with all given DSEFs and ERMFs. These results are similar to those observed in $R$. formosanum (Lin et al., 2011), R. ovatum (Lin et al., 2019) and R. Kanehirae (Lin et al., 2020). Moreover, the Rf32-inoculated seedlings exhibited the highest value of shoot/root ratio ( $\mathrm{S} / \mathrm{R} ; 5.8 \pm 2.2)$, whereas Rp7-inoculated $(2.1 \pm 1.6)$ and Rp9-inoculated $(2.1 \pm 0.9)$ seedlings exhibited the smallest $\mathrm{S} / \mathrm{R}$ among all treatments.

Similar to that of other researchers, our results also indicated that DSEFs and ERMFs remarkably affected the composition and content of the secondary metabolites of $R$. pseudochrysanthum. Previous reports demonstrated that mycorrhizal fungi, such as arbuscular mycorrhizae and DSEFs, not only promoted the growth of host plants (Johansson, 2001; Sigler et al., 2005; Lin et al., 2011) but also affected the content of secondary metabolites (Ponce et al., 2004; Zhou and Fan, 2007; Wu et al., 2010). Moreover, Martino et al. (2000) indicated that the different fungal strains had functional diversity. Similarly, the phytochemical content of host seedlings was also dependent on the fungal strains among the five endophytic fungi used in the present study. Considerable diversity was observed in the content of secondary metabolites of $R$. pseudochrysanthum seedlings inoculated with different strains of endophytic fungi.

\section{Conclusion}

Fungal strains Rf9 and Rf32 could form ERM with Rhododendron pseudochrysanthum and Rp7, Rp9, and Rp28 could form DSE with their host plants. Our study results showed that all of these inoculated seedlings showed a positive effect on growth response. In addition, the phytochemical composition and content of $R$. pseudochrysanthum was significantly influenced by these five stains. After the 12-month incubation, the DSEF Rp7 had the highest antioxidative phytochemical content in their host seedlings. Accordingly, the endophytic fungi used in our study, DSEF Rp7 had the best performance for promote the content of secondary metabolites of $R$. pseudochrysanthum seedlings.

\section{REFERENCES}

[1] Arnold, A. E., Miadlikowska, J., Higgins, K. L., Sarvate, S. D., Gugger, P., Way, A., Hosfstetter, V., Kauff, F., Lutzoni, F. (2009): A phylogenetic estimation of tropic transition networks for ascomycetous fungi: are lichens cradles of symbiotrophic fungal diversification? - Syst. Biol. 58: 283-297.

[2] Bonfante, P., Genre, A. (2010): Mechanisms underlying beneficial plant-fungus interactions in mycorrhizal symbiosis. - Nat. Commun. 1: 48.

[3] Cairney, J. W. G., Meharg, A. A. (2003): Ericoid mycorrhiza: a partnership that exploits harsh edaphic conditions. - Eur. J. Soil Sci. 54: 735-740.

[4] Chamberlain, D. F., Hyam, R., Argent, G., Fairweather, G., Walter, K. S. (1996): The genus Rhododendron: its classification and synonymy. - Royal Botanic Garden Edinburgh, Edinburgh.

[5] CLSI (2008): Interpretive criteria for identification of bacteria and fungi by DNA target sequencing; approved guideline. - Clinical and Laboratory Standards Institute, Wayne, PA.

[6] Dalpé, Y. (1986): Axenic synthesis of ericoid mycorrhiza in Vaccinium angustifoliurn Ait. by Oidiodendron species. - New Phytol. 103: 391-396. 
[7] Davies, P. W., Mclean, C. B., Bell, T. L. (2003): Root survey and isolation of fungi from alpine epacrids (Ericaceae). - Australas. Mycol. 22(1): 4-10.

[8] De Hoog, G. S., van den Ende, A. H. G. G. (1998): Molecular diagnostics of clinical strains of filamentous basidiomycetes. - Mycoses 41(5-6): 183-189.

[9] Doyle, J. J., Doyle, J. L. (1990): Isolation of plant DNA from fresh tissue. - Focus 12: 1315.

[10] Gibson, B. R., Mitchell, D. T. (2005): Influence of pH on copper and zinc sensitivity of ericoid mycobionts in vitro. - Mycorrhiza 15: 231-234.

[11] Hambleton, S., Currah, R. S. (1997): Fungal endophytes from the roots of alpine and boreal Ericaceae. - Can. J. Bot. 75: 1570-1581.

[12] Hutton, B. J., Dixon, K. W., Sivasithamparam, K. (1994): Ericoid endophytes of Western Australian heaths (Epacridaceae). - New Phytol. 127: 557-566.

[13] Johansson, M. (2001): Fungal associations of Danish Calluna vulgaris roots with special reference to ericoid mycorrhiza. - Plant Soil 231: 225-232.

[14] Jumpponen, A., Trappe, J. M. (1998): Dark septate endophytes, a review of facultative biotrophic root-colonizing fungi. - New Phytol. 140: 295-310.

[15] Jung, S. J., Kim, D. H., Hong, Y. H., Lee, J. H., Song, H. N., Rho, Y. D. (2007): Flavonoids from the flower of Rhododendron yedoense var. poukhanense and their antioxidant activities. - Arch. Pharm. Res. 30: 146-150.

[16] Lin, L. C., Lee, M. J., Chen, J. L. (2011): Decomposition of organic matter by the ericoid mycorrhizal endophytes of Formosan rhododendron (Rhododendron formosanum Hemsl.). - Mycorrhiza 21: 331-339.

[17] Lin, C. Y., Lin, L. C., Ho, S. T., Tung, Y. T., Tseng, Y. H., Wu, J. H. (2014a): Antioxidant activities and phytochemicals of leaf extracts from 10 native Rhododendron species in Taiwan. - Evid-Based Compl. Alt.

[18] Lin, L. C., Chang, L. H., Liao, I. K., Lee, T. M., Tseng, T. Y. (2014b): Morphology and endophytes of root-fungus association of Rhododendron pseudochrysanthum (R. morii) in Alishan area. - Taiwan J. Biodivers. 16(3): 253-262. [In Chinese].

[19] Lin, L. C., Ye, Y. S., Lin, W. R. (2019): Characteristics of root cultivable endophytic fungi from Rhododendron ovatum Planch. - Brazilian Journal of Microbiology 50: 185-193.

[20] Lin, L. C., Lin, W. R., Hsu, Y. C., Pan, H. Y. (2020): Influences of three Oidiodendron maius isolates and two inorganic nitrogen sources on the growth of Rhododendron kanehirae. - Hortic. Sci. Technol. 38(5): 742-753.

[21] Lukešová, T., Kohout, P., Větrovský, T., Vohník, M. (2015): The potential of dark septate endophytes to form root symbioses with ectomycorrhizal and ericoid mycorrhizal middle European forest plants. - PLoS One 10(4): e0124752.

[22] Martino, E., Turnau, K., Girlanda, M., Bonfante, P., Perotto, S. (2000): Ericoid mycorrhizal fungi from heavy metals polluted soils: their identification and growth in the presence of heavy metals. - Mycol. Res. 104: 338-344.

[23] Michelsen, A., Schmidt, I. K., Jonasson, S., Quarmby, C., Sleep, D. (1996): Leaf ${ }^{15} \mathrm{~N}$ abundance of subarctic plants provides field evidence that ericoid, ectomycorrhizal and non- and arbuscular mycorrhizal species access different sources of soil nitrogen. Oecologia 105: 53-63.

[24] Nirmala, P., Ramanathan, M. (2011): Effect of kaempferol on lipid peroxidation and antioxidant status in 1,2-dimethyl hydrazine induced colorectal carcinoma in rats. - Eur. J. Pharmacol. 654: 75-79.

[25] Okane, I., Srikitikulchai, P., Tabuchi, Y., Sivichai, S., Nakagirl, A. (2012): Recognition and characterization of four Thai xylariaceous fungi inhabiting various tropical foliages as endophytes by DNA sequences and host plant preference. - Mycoscience 53: 122-132.

[26] Piercey, M. M., Thormann, M. N., Currah, R. S. (2002): Saprobic characteristics of three fungal taxa from ericalean roots and their association with the roots of Rhododendron groenlandicum and Picea mariana in culture. - Mycorrhiza 12: 175-180. 
[27] Ponce, M. A., Scervino, J. M., Erra-Balsells, R., Ocampo, J. A., Godeas, A. M. (2004): Flavonoids from shoots and roots of Trifolium repens (white clover) grown in presence or absence of the arbuscular mycorrhizal fungus Glomus intraradices. - Phytochemistry 65: 1925-1930.

[28] Qiang, Y., Zhou, B., Gao, K. (2011): Chemical constituents of plants from the genus Rhododendron. - Chem. Biodivers. 8(5): 792-815.

[29] Rice, A. V., Currah, R. S. (2001): Physiological and morphological variation in Oidiodendron maius. - Mycotaxon 79: 383-396.

[30] Schmid, E., Oberwinkler, F., Gomez, L. D. (1995): Light and electron microscopy of a host-fungus interaction in the roots of some epiphytic ferns from Costa Rica. - Can. J. Bot. 73: 991-996.

[31] Sigler, L., Allan, T., Lim, S. R., Berch, S., Berbee, M. (2005): Two new Cryptosporiopsis species from roots of ericaceous hosts in western North America. - Stud. Mycol. 53: 5362.

[32] Tseng, Y. H., Lu, S. Y. (2003): Introduction of Rhododendron spp. in the field. - Nat. Conserv. Quart. 43: 18-30. [In Chinese].

[33] Upson, R., Read, D. J., Newsham, K. K. (2007): Widespread association between the ericoid mycorrhizal fungus Rhizoscyphus ericae and a leafy liverwort in the maritime and sub-Antarctic. - New Phytol. 176: 460-471.

[34] Usuki, F., Narisawa, K. (2005): Formation of structures resembling ericoid mycorrhizas by the root endophytic fungus Heteroconium chaetospora within roots of Rhododendron obtusum var. kaempferi. - Mycorrhiza 15: 61-64.

[35] Vilgalys, R., Hester, M. (1990): Rapid genetic identification and mapping of enzymatically amplified ribosomal DNA from several Cryptococcus species. - J. Bacteriol. 172: 42384246.

[36] Vohník, M., Albrechtová, J. (2011): The co-occurrence and morphological continuum between ericoid mycorrhiza and dark septate endophytes in roots of six European Rhododendron species. - Folia Geobot. 46: 373-386.

[37] Wei, X., Chen, J., Zhang, C., Pan, D. (2016): A new Oidiodendron maius strain isolated from Rhododendron fortunei and its effects on nitrogen uptake and plant growth. - Front. Microbiol. 7: 1327.

[38] Wei, X., Chen, J., Zhang, C., Liu, H., Zheng, X., Mu, J. (2020): Ericoid mycorrhizal fungus enhances microcutting rooting of Rhododendron fortunei and subsequent growth. - Hortic. Res. 7: 140.

[39] Wu, Z. Y., Lu, A. M., Tang, Y. C., Chen, Z. D., Li, D. Z. (2003): The Families and Genera of Angiosperms in China. - Sci. Press, Beijing.

[40] Wu, L., Lv, Y., Meng, Z., Chen, J., Guo, S. X. (2010): The promoting role of an isolate of dark-septate fungus on its host plant Saussurea involucrata Kar. et Kir. - Mycorrhiza 20: 127-135.

[41] Yang, H. B., Fang, R. C., Jin, C. L. (1999): Ericaceae. - In: Fang (ed.) Flora Reipublicae Popularis Sinicae. Sci. Press, Beijing.

[42] Zhou, J. H., Fan, J. H. (2007): Effects of AM fungi on the berberine content in Phellodendron chinense seedings. - North. Horticult. 12: 25-27. [In Chinese]. 